\title{
A linguagem fotográfica no projeto em design: as mudanças tecnológicas das ferramentas de captura fotográfica
}

The photographic language in the design project: the technological changes of the photographic capture tools

SILVA, Júlio César Riccó Plácido da; Doutorando; Faculdade de Arquitetura e Urbanismo da Universidade de São Paulo - FAU/USP

julioricco@usp.br

TARALLI, Cibele Haddad; Doutora; Faculdade de Arquitetura e Urbanismo da Universidade de São Paulo - FAU/USP

cibelet@usp.br

\section{Resumo}

Sabendo da importância da linguagem fotográfica em diversas áreas do conhecimento, este artigo dá prosseguimento a pesquisas sobre a evolução, a atualidade dos processos fotográficos para e no design de produto; adota procedimentos de pesquisa de levantamento bibliográfico em fontes impressas e virtuais para condução das mudanças tecnológicas na linguagem e nos dispositivos fotográficos atuais e usa dados coletados em levantamentos de campo em instituições de ensino sobre o estado do conhecimento, o aprendizado e as aplicações da linguagem fotográfica nos cursos de graduação em design de produto do Estado de São Paulo.

Palavras Chave: linguagem fotográfica; formação em design; design de produto e design.

\begin{abstract}
Knowing the importance of the photographic language in several areas of knowledge, this article continues research on the evolution, the actuality of the photographic processes for and in product design; adopts bibliographical survey research procedures in printed and virtual sources for conducting of the technological changes in the language and in the current photographic devices and uses data collected in field surveys in educational institutions on the state of knowledge, learning and application of the photographic language undergraduate courses in product design of the São Paulo State.
\end{abstract}

Keywords: photographic language; design training; product design and design. 


\section{Introdução}

No campo do design, os sistemas de captura fotográfica desenvolvem significativa contribuição durante as fases do projeto ao estabelecer uma comparação entre o objeto e a sua representação através da imagem. Entretanto com as tecnologias digitais recentes empreendidas nesta área, coloca-se a pergunta - Como as mudanças dos sistemas de captura (analógico/mecânico x digital/eletrônico) estão interferindo na aplicação das ferramentas em uso no Design de Produto?

Tradicionalmente, o sistema de captura de imagens fotográficas vem desempenhando papel de representação de imagens em aplicações usuais no projeto e na modelagem, aplicados no registro, memória, referências semânticas ou sintáticas, na documentação no projeto de produto e dos próprios objetos e artefatos produzidos, mas também, vem colaborando como instrumento auxiliar no processo projetual, considerando as fases criativas até as de divulgação de resultados.

Ocorre que outros recursos tecnológicos contemporâneos que incorporam tecnologia digital, adicionam e auferem potencial como linguagem e não somente como meio de representação, além de abrir possibilidades para a atuação em design de produto, em processos de análise, avaliação, redesenho e novas propostas. Desta forma, com o advento computacional, as tecnologias digitais oferecem novos recursos, ao mesmo tempo em que provocam uma busca incessante dos profissionais e estudantes pelas informações necessárias para aderirem a tais técnicas em suas práticas e pesquisas.

Diversos equipamentos, máquinas e dispositivos, como câmeras (DSLR ${ }^{1}$ ou Mirrorless ${ }^{2}$ ), smartphones, tablet, filmadoras eletrônicas/digitais, incorporam padrões de captura de imagem fixa e em movimento, desenvolvidos pelas marcas comerciais, auferindo ou não a possibilidade de ajuste ou opções de uso, implicando no maior ou menor domínio do operador neste processo de controle das características e parâmetros desejados, no instante da tomada da imagem.

Considera-se que no design, a busca por domínio técnico e conhecimento operativo pode e deve gerar novas variações em pesquisa, representação, estudo e manipulação de imagens nos processos de projeto, de maneira que suas possibilidades não se tornem massificados ou padronizados pelos parâmetros já inseridos nos equipamentos, possibilitando ao designer ter maior flexibilidade no uso, na manipulação e na geração de imagens, atendendo às diferentes necessidades durante as etapas do projeto.

O desenvolvimento da linguagem fotográfica representa na atualidade um papel importante e significativo principalmente no conhecimento e na operação das ferramentas e recursos tecnológicos, associados ou não a programas e meios digitais aplicados à captura, manipulação, tratamento e proposições de ideias para o design de produto, no quesito da geração e da comunicação por imagens.

Este artigo dá prosseguimento a pesquisas sobre a evolução, a atualidade dos processos fotográficos para e no design de produto; adota procedimentos de pesquisa de levantamento bibliográfico em fontes impressas e virtuais para condução das mudanças tecnológicos na

\footnotetext{
${ }^{1}$ Câmera digital que usa um sistema mecânico de espelhos e um pentaprisma para direcionar a luz da lente para um visor óptico na parte traseira da câmera.

${ }^{2}$ Câmera fotográfica que não possuí espelho.
} 
linguagem e nos dispositivos fotográficos atuais; e usa dados coletados em levantamentos de campo em instituições de ensino paulistas sobre o estado do conhecimento, o aprendizado e as aplicações da linguagem fotográfica nos cursos de graduação em design de produto ${ }^{3}$.

Sabendo que as ferramentas de captura auxiliam nos processos de investigação do designer o objetivo do estudo é apresentar como a mudança de tecnologia de captura (fotografia e vídeo) vem sendo rebatida no uso das ferramentas pelos designers de produto, interferindo nas aplicações técnicas, principalmente na produção de imagens para o projeto, intervindo nas habilidades e competências necessárias para a formação do Designer de Produto.

\section{Progresso do processo fotoquímico ao processo eletrônico}

A partir do Renascimento, as paisagens presentes nos quadros de diversos artistas se tornaram cada vez mais conscientes, sólidas, simetricamente conceituadas, funcionais e matematicamente alinhadas. O objetivo era criar uma imagem cientificamente plausível, uma ilusão do real, utilizando-se de ferramentas diversas para obter uma representação concisa de profundidade, colaborando para construir as bases da fotografia analógica. (MACHADO, 2002).

A pintura, resultado de um longo processo criativo e aditivo, podia subitamente ser substituída por um rápido processo óptico, mecânico e químico. A imagem fotográfica não constituiu, inicialmente, uma ameaça direta à pintura. O seu formato era limitado ao que a objetiva conseguia alcançar, as imagens eram em preto e branco e o processo dependia da iluminação (BEIGER-THIELEMANN,1996).

O desenvolvimento tecnológico e a criação de novas técnicas de produção e reprodução de imagens propiciaram a proliferação das mesmas, contribuindo decisivamente e constantemente, para o esquecimento da fotografia como uma construção de um saber e de habilidade na manipulação do dispositivo.

Com todas essas possibilidades, o usuário passa a experimentar diversos dispositivos técnicos desenvolvidos para gerar imagens cientificamente verossímeis. Para conseguir tais objetivos, um número incontável de máquinas é desenvolvida.

A evolução da fotografia buscou, a partir de uma pesquisa quase que obsessiva, automatizar cada vez mais os processos de criação e reprodução da imagem, preocupação que se iniciou primeiramente entre pintores e artistas (COUCHOT, 1999). A automatização do processo de captura não progrediria sem o domínio das ferramentas aliado o saber e as habilidades do fotógrafo. Essa decomposição não era, a princípio, automatizável e a busca do menor elemento ${ }^{4}$ só foi superada graças ao cálculo automático do computador, dominando totalmente o ponto da imagem. Devido a essa automatização, Couchot (1999) nomeou essa evolução do processo representativo de "nova ordem visual".

Esse processo do domínio do menor elemento só foi possível através de uma correlação

\footnotetext{
${ }^{3}$ Esta pesquisa integra investigações da tese de Doutorado em andamento pelo autor deste artigo na Faculdade de Arquitetura e Urbanismo da Universidade de São Paulo, sobre Linguagem fotográfica e Representação em Design de Produtos, orientado pela Prof ${ }^{a}$. Dr $^{a}$. Cibele Haddad Taralli.

${ }^{4}$ Pixel é o menor ponto que forma uma imagem digital, sendo que o conjunto de pixels formam a imagem inteira.
} 
entre o ruído digital e o grão de filme (imagem 1), onde o desenvolvimento tecnológico aproxima ambas tecnologias com relação a luz e a ausência dela.

Imagem 1 - Ruído digital versus grão do filme

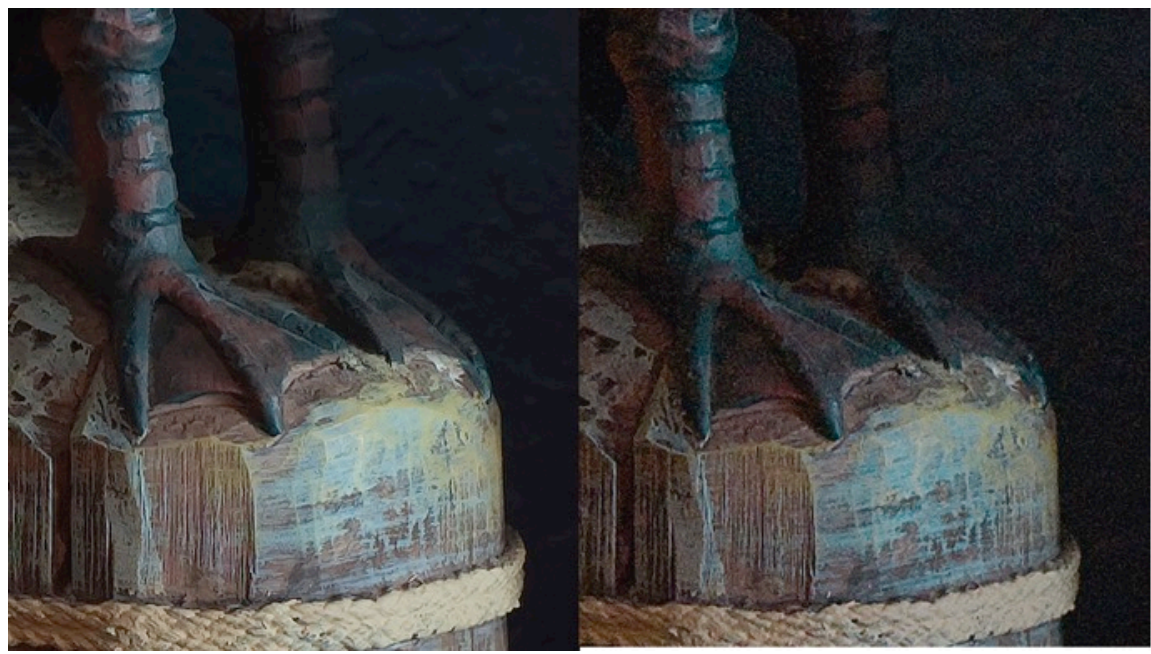

Fonte: <https://thewayeyeseesit.com/2013/01/18/digital-noise-versus-film-grain-a-short-primer-fornewbies/> - acesso em 19 de março de 2018

Entretanto para Dubois (2004) a única diferença e que agora esta imagem digital (virtual) não passa de uma das soluções já programadas pelo sistema dos dispositivos, máquinas e ferramentas, onde o indivíduo realiza sua captura seguindo as programações da ferramenta, e o operador fica praticamente sem opção na tomada de decisão sobre como, e quais parâmetros qualitativos são necessários, ou desejáveis, para realizar a captura a da imagem. O processo se torna automatizado.

O percurso da fotografia é marcado por diversos aprimoramentos técnicos, que procuram atender às necessidades da sociedade e com o desenvolvimento tecnológico é clarividente que o caminho a ser trilhado ainda é muito extenso, pois o equipamento fotográfico eletrônico oferece padrões diferentes em novas possibilidades expressivas para a criação, sendo hoje consideradas inesgotáveis e imprevisíveis as contribuições futuras, tanto para o produto da imagem, como: para as possibilidades de pesquisa para a criação; como referência visual; uso no processo criativo; na documentação das fases de processo de projeto; em imagens técnicas precisas; para análise e pesquisa de uso do produto; para análise através do vídeo e análise e prospecção de uso do produto.

Com todos estes recursos à disposição, identifica-se, portanto, a necessidade de apropriação da técnica, de construção de habilidades, e da aquisição de conhecimentos para a interferência nos sistemas digitais fotográficos (e nos sistemas dos dispositivos) ainda no processo de formação dos designers.

A imagem eletrônica é muito mais flexível, ou seja, aberta a modificações, que a imagem fotoquímica. Devido às diversas possibilidades de manipulação, é possível reescrever seu código e assim constituir imagens com fortes elementos de linguagem, através da manipulação de seus recursos, compreendendo a necessidade de usar técnicas específicas para cada captura e a interferência através de programação em softwares apropriados. 


\section{Impacto das mudanças do sistema de captura e manipulação}

Os aspectos funcionas das ferramenta de captura apresentam um ocultamento que se dá tanto pelo excesso de imagens como pela convergência tecnológica das ferramentas existentes e pela facilidade de manipulação e captura. Entretanto, a credibilidade da captura se deu pelo fato da realidade ser apreendida e é "... percebida como uma espécie de prova, ao mesmo tempo necessária e suficiente, que atesta indubitavelmente a existência daquilo que mostra." (DUBOIS, 1998, p.25). Desta maneira instaura-se o seu caráter documental de maneira fiel à realidade capturada, apresentando assim uma ferramenta de extrema importância para diversos campos e, dessa forma, mantém ou dá continuidade aos processos analógicos.

Contudo, para Machado (2001), a captura de imagem só existe quando há intenção de produzi-la e quando quem a deseja detém um conhecimento específico do aparato técnico e das ferramentas disponíveis e recentes para aplica-la já no processo de projeto, além da comunicação de resultados, ampliando as possibilidades de atuação do designer.

A imagem perde sua aura, ao mesmo tempo em que aumenta o seu potencial expositivo, nesse sentido o excesso de imagens vem crescendo devido ao complexo sistema de comunicação visual, associado ao rápido desenvolvimento das redes computacionais, colocando em movimento uma revolução midiática (SOBRAL, 2011). Desta maneira a representação digital supera a era química popularizando os processos digitais em larga escala. Baudrillard (1984) afirma que o que está em jogo não é uma mudança tecnológica e sim uma mudança na forma de ver o mundo, consequentemente, as maneiras de como as ferramentas estão sendo utilizadas. As possibilidades de capturas estão sendo modificadas e ampliadas conforme as tecnologias avançam.

Essa mudança de formato (analógico/mecânico x digital/eletrônico) gerou uma grande ruptura em todo o sistema da linguagem fotográfica, uma revolução como a invenção da própria fotografia, e não somente o nascimento de uma nova ferramenta e as possibilidades de hibridização de diversas tecnologias em um único dispositivo e que estão sendo ampliadas pelos algoritmos e aplicativos desenvolvidos em conjunto aos processos de captura.

Para realizar a captura de maneira analógica é necessário utilizar filmes de acetato recoberto com sais de prata, enquanto hoje a câmera digital cumpre uma nova função com os sensores para captação de luz substituindo os filmes, sendo que a imagem capturada que é armazenada em cartões de memória deixa de ser fotoquímica e passa a ser fotoelétrica (como nos smartphone e tablet).

Diante dessas mudanças e da oferta de novos modos de gerar e manipular imagens, operados dentro de um contexto de internacionalização tecnológica, se considera e se requer uma atitude principalmente de capacitação e de acesso ao conhecimento e a prática, demandando infraestrutura com grandes investimentos, como bens materiais e principalmente capacitação de docentes e técnicos para oferecer ao aluno as novas possibilidades das ferramentas, fomentando a investigação e as aplicações no campo do Design de produto, desde a pesquisa de dados, à criação e o desenvolvimento do produto, e também outras possibilidades de atuação em análises e avaliações, prospecção e experimentação em produtos.

Para Sobral (2011) essas discussões travadas sobre as mudanças tecnológicas digitais e sua natureza, parecem refletir a dualidade ontológica e epistemológica que marcou toda história da 
representação fotográfica. Embora reconhecida como um invento científico, sua prática está ligada a uma atividade artesanal de conhecimento prático e artístico dentro do campo do Design (SILVA e TARALLI, 2016).

Desta maneira a revolução tecnológica interferiu nos sistemas de captura de imagem que são de grande importância para os designers, como registro de um fragmento do tempo (documento) e de estrema importância como ferramenta auxiliar para as várias fases do processo de projeto.

\section{O papel da imagem digital no ensino de design de produto}

Para os docentes e técnicos que vivenciaram o processo analógico e transmitiram esses conhecimentos e métodos por tanto tempo dentro de instituições de ensino, assumir estas mudanças nem sempre é ação imediata, pois se deparam atualmente com a tarefa de migrar para o outro sistema deixando ou subutilizando o anterior. Esse abandono da tecnologia anterior (papel sensível, filmes, químicos, ampliadores e câmera analógica) não é apenas pelo fato do mecânico ser inferior ou obsoleto, mas sim pela dificuldade na obtenção de recursos materiais e humanos, pelos valores dos suprimentos necessários para atualizar as ferramentas e processos digitais e pelas adaptações necessárias para seu emprego em atividades ligadas aos processos de ensino aprendizagem.

O desaparecimento da fotografia analógica não significa o fim do aparato fotográfico, nem mesmo da sua antiga base tecnológica: a câmara escura passa agora pela sua segunda grande mudança. A primeira, quando a velha câmara escura, usada para observar o reflexo do mundo, passou a ter também a função de fixá-lo por meio dos filmes fotográficos, e a segunda que estamos vivenciando agora, com a mudança da tecnologia analógica para a digital (SOBRAL, 2011, p.28).

Outra questão é o processo para armazenar, gerenciar e descartar o material químico utilizado, que era realizado por algumas empresas que não atuam mais nesse ramo, acarretando na possiblidade de penalidades estaduais e federais na eliminação ilegal destes resíduos (reveladores - hidroquinona pura, que produz o contraste e não pode ser descartado no meio ambiente).

Essa mudança para o sistema digital transformou a câmara escura em câmara clara, considerando os diferentes dispositivos digitais disponíveis (com ou associado ao uso de softwares de edição e tratamento como, por exemplo, o lightroom - figura 2, a camera raw - figura 3, e o photoshop - figura 4 entre outros).

Figura 2 - Tela do software lightroom: software especifico para tratamento em lotes de imagens 


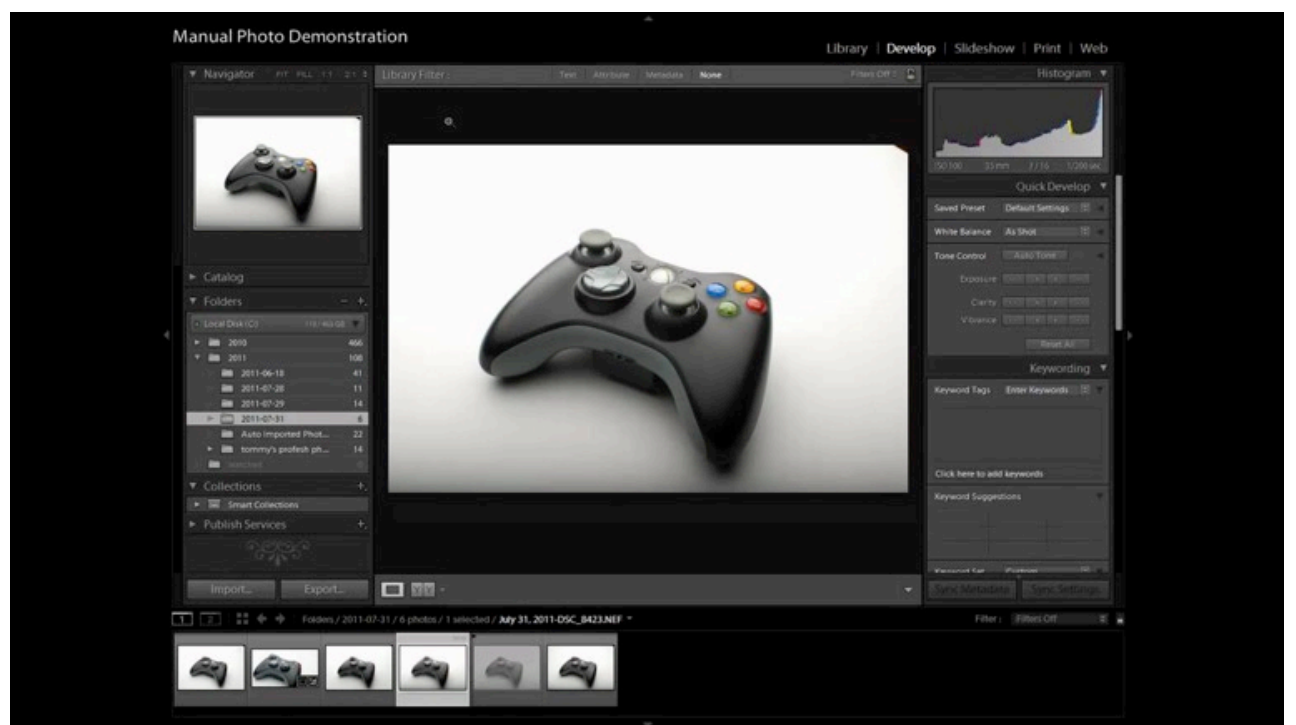

Fonte: < https://goo.gl/images/m5u2Cm> - acesso em 19 de março de 2018

Figura 3 - Tela do câmera raw - sistema que permite importar e aprimorar imagens de alta definição

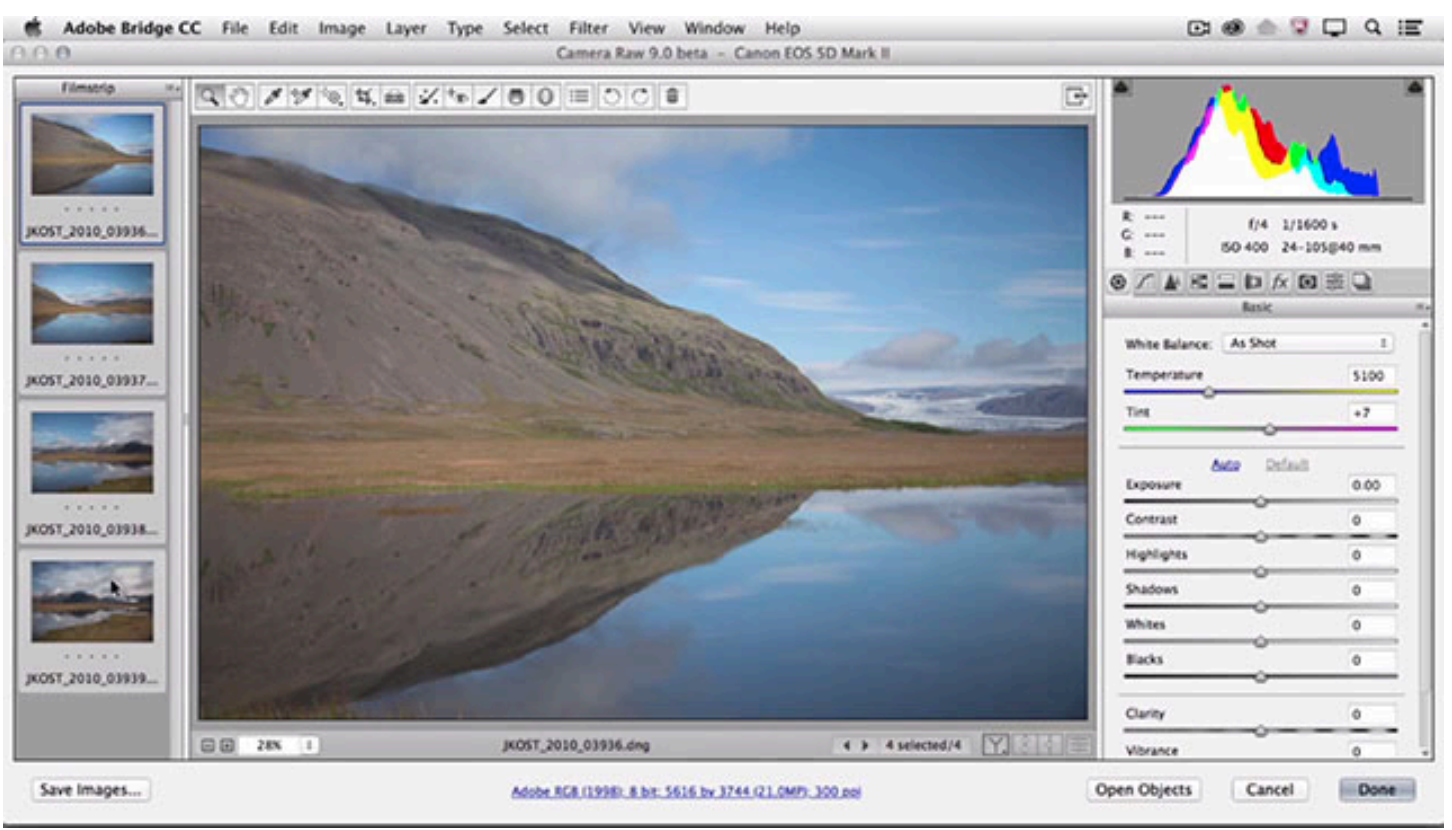

Fonte: < https://petapixel.com/assets/uploads/2015/04/acr91.jpg> - acesso em 19 de março de 2018

Figura 4 - Tela do Adobe Photoshop com opções para tratamento de imagem 


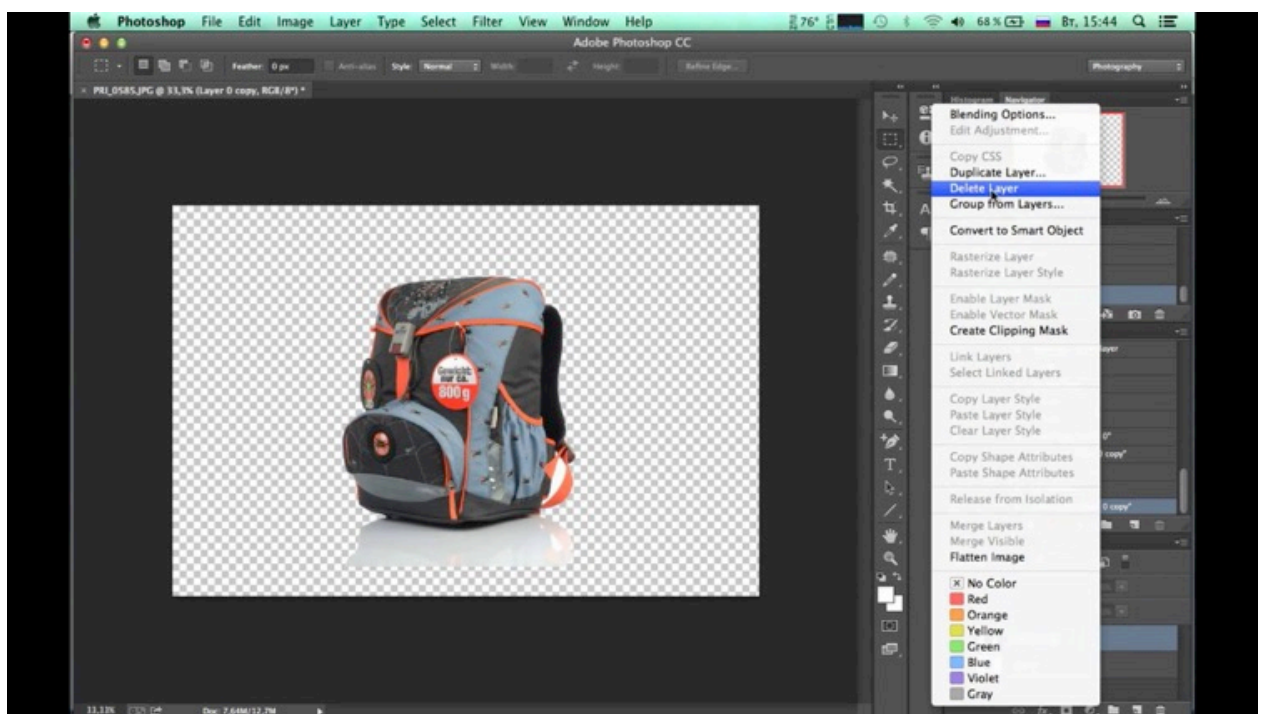

Fonte: <https://goo.gl/images/PAg1aj> - acesso em 19 de março de 2018

Ressalta-se também que as possibilidades de manipulação da imagem requerem o domínio do menor elemento da imagem digital o pixel, que possibilita uma gama inimaginável de controle no momento da captura, abrindo novos caminhos, ampliando ainda mais a resolução tridimensional com o voxel, que são pequenos cubos que preenchem o objeto para simulações físicas e animações, mais utilizado na visualização e análise de dados médicos, científicos e jogos digitais.

Ainda em relação às tecnologias digitais também entram outros sistemas de captura, disponíveis para o trabalho em design de produto (como o scanner tridimensional - figura 5, a termografia infravermelha - figura 6 e a realidade aumentada - figura 7).

Figura 5 - Scanner tridimensional: captura da nuvem de pontos por imagens de produto

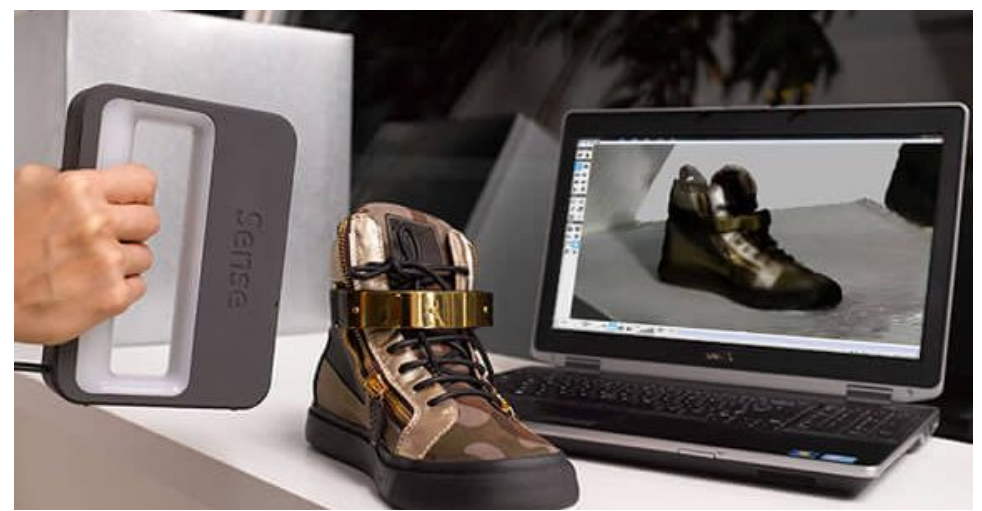

Fonte: < http://www.versusdesign.com.br/wp-content/uploads/2016/06/Sense-Scanner-3D-Systems-Portatil576x300.jpg > - acesso em 19 de março de 2018

O processo de digitalização tridimensional tem um papel importante não apenas no processo de reconstrução e recuperação 3D de objetos, mas, sobretudo na área do Design de 
Produto torna possível realizar ensaios; testes; verificação; manipulação; construção de moldes; tratamento; estudos; análises volumétricas; parte do processo de engenharia reversa; armazenamento digital; inspeção como controle de qualidade; enriquecimentos visuais (sombras, reflexos, brilho, cores, textura, iluminação); simulação de animação; correção de modelos; cópia de modelos existentes e documentação de produtos; etc., que não impliquem na perda dos pontos da estrutura tridimensional, uma vez que o modelo digital pode ser inúmeras vezes recuperado, ampliando as possibilidades de criação no processo de projeto.

Figura 6 - Exemplo de Termografia Infravermelha aplicada a produto

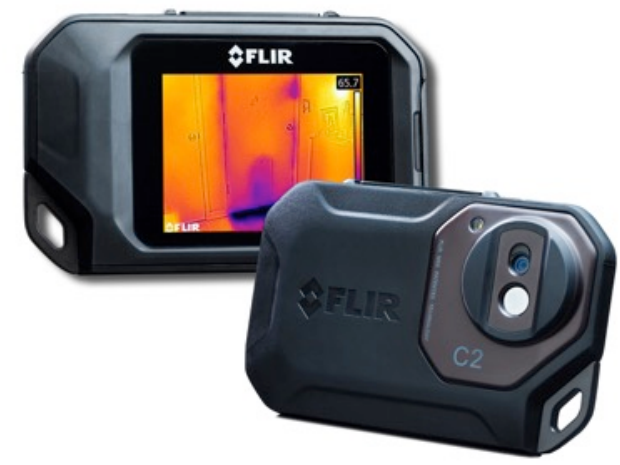

Fonte:

<http://www.instrumbrasil.com.br/config/imagens_conteudo/produtos/imagensSGRD/SGRD_39_008_C2frontback.jp g> - acesso em 19 de março de 20182018

São diversas as aplicações da ferramenta atualmente, e verifica-se sua importância em gerar informações sobre corpo humano na interface do contato com os objetos por transferência de calor; e na avaliação das propriedades de um material, para identificação de pontos de atrito na geração de calor entre partes dos materiais empregados nos objetos.

Figura 7 - Exemplo de Realidade Aumentada aplicada a produto

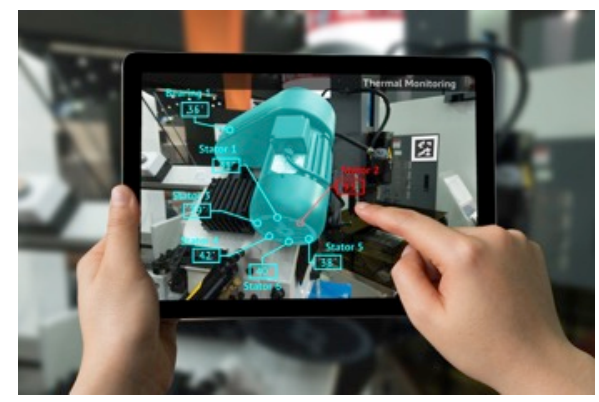

Fonte: <http://cdn.avozdaindustria.com.br/wp-content/uploads/2017/03/realidade-aumentada-manufatura-a-vozda-industria.jpg > - acesso em 19 de março de 2018 
Segundo Cardoso et. al. (2007) a RA é uma amplificação da percepção sensorial por meio de recursos computacionais, sendo assim uma tecnologia para exibir elementos digitais em um ambiente real em tempo real. O Design pode utilizá-la como uma ferramenta de alto potencial, auxiliando e reduzindo custos no processo de projeto.

Para Sobral (2011) o surgimento da tecnologia digital e de novas formas de captação, gravação e armazenamento de imagens, produziu um processo de construção imagética a partir de base matemática.

Como a câmera digital e o software de processamento assumiu o lugar das tradicionais técnicas fotográficas, pode-se dizer que a fotografia vive um momento de expansão, no que diz respeito tanto ao incremento de suas possibilidades expressivas quando às mudanças em sua conceitualização teórica (MACHADO, 2001, p. 134).

Entretanto Sobral (2011, p. 28) acredita que:

[...] a tecnologia analógica, com determinadas limitações e potenciais, coexiste e coexistirá por muito tempo com a tecnologia digital, e mesmo que um dia venha desaparecer, a imagem fotográfica continuará existindo.

Mesmo com essa coexistência o futuro das ferramentas no ensino dependerá de adaptações e da flexibilidade dos docentes e técnicos em relação às práticas, existentes que passaram por grandes transformações, e estarão sempre recebendo novas modificações tecnológicas. E para os alunos, a instrumentação e a experimentação dependerão do acesso, do conhecimento e das oportunidades de uso no ambiente de ensino e pesquisa.

Como já mencionado anteriormente, essas modificações estão sendo realizadas principalmente pelas possibilidades de captura hibridizadas nos smartphones, tablet e console portátil (videogame), onde todo o processo está integrado em uma única ferramenta (captura, armazenamento e transmissão).

Desta maneira, dentro das instituições de ensino, o papel da imagem digital aplicada ao projeto de produtos é fundamental como meio de criação, desenvolvimento e representação, mas, se pondera que ao assumir exclusivamente os dispositivos analógicos não se procura garantir a aceitação e uma transição tecnológica necessária, que possivelmente não está acontecendo devido ao distanciamento das instituições de ensino e dos profissionais dos avanços tecnológicos, gerando uma defasagem, uma vez que fica mantido o uso e a instrumentação analógica.

Já fora das instituições essa transição foi mais sutil, mais difundida na sociedade, ocorrendo ao lado de aplicações especializadas como a utilização de scanners de alta precisão de negativos para o sistema digital (scanner de tambor para negativos ou diapositivos - figura 8), potencializando a tecnologia já existente, que aos poucos foi sendo modificada com a incorporação completa do sistema digital. 


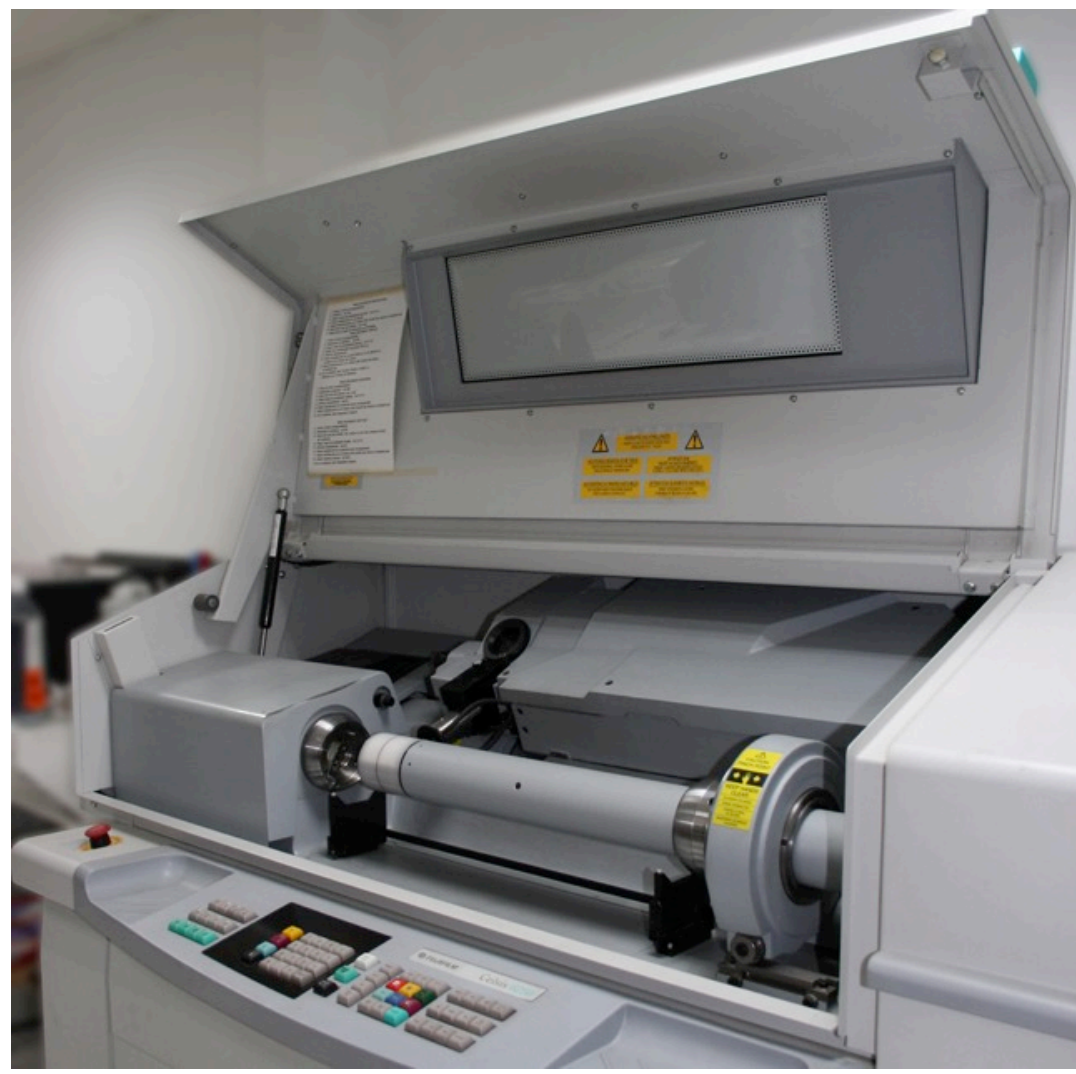

Fonte: <https://argdismorenopreimpresion.files.wordpress.com/2012/03/scanner_tambor_0126.jpg> - acesso em 19 de março de 2018

Para Machado (2001) a câmera digital e o software de processamento vem assumindo o lugar das tradicionais técnicas fotográficas, e pode-se dizer que a fotografia vive um momento de expansão, no que diz respeito tanto ao incremento de suas possibilidades expressivas quanto às mudanças em termos de conceitualização teórica.

O importante é mencionar que a captura de imagem é uma atividade técnica de extrema precisão, e ao mesmo tempo lembrar que hoje essa pericia não é mais requerida, e até foi popularizada e amplamente disseminada na sociedade devido a automação dos sistemas (MACHADO, 2001). Entretanto não é só na captura automática que se requer aprendizado e habilidade para o designer de produto.

Outra questão é a diferenciação de requisitos na formação em design entre as habilidades para o produto e as áreas visuais: representar no design gráfico diferencia-se do design de produto onde a captura fotográfica ou em vídeo tem por objetivo representar o instante, a fim de ficar verossímil e fielmente ao percebido, se aproximando ou interpretando objetos, produtos e instalações com proporções corretas, ou ainda promovendo ações do sujeito utilizando objetos em situações reais ou simuladas de uso. Já nas atividades gráficas e outras atuações de natureza visual, como games, peças gráficas e de comunicação visual, os procedimentos de captura, de manipulação e tratamento de imagem atuam mais na simulação, na criatividade do que na representação fiel (ou perceptível).

A pesquisa de campo desenvolvida no Estado de São Paulo em 17 instituições de ensino, 
entrevistando 33 professores e 69 alunos (entre 2016 e 2017) identificou a falta de instrumentação e uso de ferramentas mais modernas em termos de tecnologias inseridas e à disposição no ensino da graduação, verificada em currículos, disciplinas, laboratórios e outras atividades como oficinas ou workshops, que constituem atividades importantes para que o aluno possa aprimorar suas habilidades para utilização no campo.

Com o constante desenvolvimento tecnológico, estão à disposição novas ferramentas para a utilização em novos procedimentos, sendo fundamental que durante a formação acadêmica, o aluno tenha contato experimental e conheça as possibilidades dos recursos oferecidos pelos diversos dispositivos e programas digitais (e analógicos) de captura para que, posteriormente, saiba eleger ou até mesmo modificar as perspectivas ou expectativas em relação aos meios de representações e linguagens fotográficas existentes, auxiliando e ampliando a sua capacidade de percepção visual, com o conhecimento de técnicas apreendidas.

Os cursos existentes no Estado de São Paulo, que sejam estadual ou municipal, assim como os particulares, não acompanham o ritmo do desenvolvimento tecnológico da indústria que se encontra em constante expansão e aprimoramento, conforme demonstrado nos resultados das pesquisas já mencionadas, situação que pode ser agravada pelo alto investimento representado na aquisição e disponibilização de equipamentos, programas e recursos como laboratórios e oficinas.

As modificações introduzidas nas ferramentas de captura (digitais) dificultaram fomentar a competência cognitiva, devido aos resultados automáticos por elas produzidos, não dando sequência ao desenvolvimento de capacidades e habilidades existentes no pensar em e por imagens, conteúdos estes que devem ser trabalhados em disciplinas voltadas ao ensino da linguagem fotográfica, e não somente serem valorizadas pelos docentes apenas nas apresentações finais dos projetos. Os dados apurados nos levantamentos de campo indicam que 95,7\% das instituições oferecem disciplinas de fotografia ou de vídeo em sua grade curricular; e apenas 4,3\% não as ministra, sendo que mesmo presentes no currículo, estas não estão necessariamente direcionadas para a formação alunos em Design de Produto.

Ainda se pondera que existem grandes possibilidades de desvio de interpretação sobre o enfoque e o conteúdo das disciplinas, pois fica evidente nessa questão, que a fotografia e o vídeo estão mais relacionados à imagem do que ao projeto, abrangendo outras competências em Design com uma maior aproximação à arte, comunicação visual, imagem em movimento, animação, etc. No entanto, é evidente também que grande parte dos alunos se utiliza das ferramentas fotográficas apenas como meio de representação auxiliar na apresentação dos projetos, em painéis expositivos, relatórios e pranchas para entrega dos trabalhos finais, deixando de explorar outras possibilidades no processo de projeto, dentro de laboratórios voltados à pesquisa e inserção de tecnologias (maquinário e programas) mais contemporâneas, que auxiliem o processo investigativo, e instrumentem a diversidade de aplicações para o campo de atuação em questão.

Considera-se que o uso de softwares e ferramentas de captura para o ambiente virtual e de tratamento de imagens tem auxiliado o designer na execução de modelos e na visualização de materiais, e é quase impossível imaginar a prática e ensino sem estes recursos que deveriam estar contemplados no currículo da graduação (disciplina; oficina; laboratório; pesquisa, experimentação, entre outros recursos pedagógicos).

De fato, ao longo da história, as conquistas técnicas trouxeram novos territórios para o 
design que, entretanto, não estão sendo explorados dentro das instituições de ensino. Para atender as questões aqui colocadas, a proposição de uma disciplina específica sobre linguagem fotográfica (apoiada, ou em consonância com o processamento, ou ainda a programação computacional), aplicada ao projeto de produto, poderia suprir parte das necessidades de conhecimento e instrumentação, ao lado de outros recursos didáticos, como a participação em oficinas e/ou laboratórios.

\section{Considerações Finais}

Desta forma, este trabalho parte da premissa que a linguagem fotográfica constitui recurso adicional e pertinente para aplicação no projeto de produto, representando uma ferramenta potencial para uso desde a pesquisa, a manipulação, e o tratamento de imagens para o design de produto, considerado da concepção à viabilização da ideia, e também na comunicação de resultados projetuais.

Durante a formação acadêmica, além de diversos conteúdos teórico-práticos, devem-se priorizar o domínio dos métodos projetuais, das técnicas de criatividade e das experimentações com exercícios práticos de projeto e de simulações de desenvolvimento de produto, onde as ferramentas de captura fotográfica podem constituir recursos qualitativos em saberes e práticas, ampliando a qualidade da aprendizagem. Esses avanços impulsionam o surgimento de um novo cenário que atenta para o futuro e empreende uma grande transformação nos processos de projetação e de atuação em design de produto.

O sistema de captura das ferramentas digitais vem passando por profundas transformações provocadas pelas mudanças tecnológicas, que interferem e afetam todo o processo de ensino e aprendizagem da linguagem fotográfica nos cursos de graduação, requerendo novas contribuições em investigações para uma imediata promoção de melhorias no ensino, tendo como meta a formação do Designer de Produto. Desta maneira nota-se que as tecnologias não são neutras quando emergem novas descobertas e aplicações e estas se alteram em ciclos constantemente, necessitando de novas formas para sua adoção dentro do campo.

Se destaca que é importante compreender a importância da participação da linguagem fotográfica como meio estratégico e potencial para o ensino do design de produto, lembrando a necessidade da promoção de revisões constantes (e de maneira radical) das experiências didáticas a fim de aperfeiçoa-las na e para as áreas do ensino, da prática e da pesquisa.

Instrumentalizar o aluno com a aplicação das novas ferramentas de captura é promover novas possibilidades de decodificação e ampliação de processos de criação, simulação de projeto, procedimentos de busca de informações, testes e verificação, que emergem de práticas de projeto, ampliando a competências e habilidades do aluno de Design de Produto.

\section{Referências}

BAUDRILLARD, Jean. Cultura y simulacro. Barcelona: Kairós, 1984.

BEIGER-THIELEMANN, M.; et al. Fotografia do Século XX: Museum Ludwig de Colónia. Lisboa: Taschen, 1996. 
CARDOSO, Alexandre et al. Tecnologias e ferramentas para o desenvolvimento de sistemas de realidade virtual e aumentada. Editora Universitária UFPE, p. 1-19, 2007.

DUBOIS, Philippe. Cinema, video, Godard. São Paulo: Cosac Naify, 2004.

DUBOIS, Philippe. O Ato Fotográfico. 2 ed. Campinas: Papirus, 1998.

MACHADO. A. As imagens técnicas: da fotografia à síntese numérica. In: . Précinemas e póscinemas. Campinas: Papirus, 2002.

MACHADO. A. O quarto iconoclasmo e outros ensaios hereges. Rio de Janeiro: Rios Ambiciosos, 2001.

SILVA, Júlio César Riccó Plácido da; TARALLI, Cibele Haddad; "ASPECTOS HISTÓRICOS DA FOTOGRAFIA NA BAUHAUS: LINGUAGEM E MEIOS DE REPRESENTAÇÃO NOS CURSOS DE DESIGN DE PRODUTO", p. 2795-2806 . In: Anais do 12을 Congresso Brasileiro de Pesquisa e Desenvolvimento em Design [Blucher Design Proceedings, v. 9, n. 2]. São Paulo: Blucher, 2016.

SOBRAL, João Eduardo Chagas; Farbiarz, Jackeline (Orientadora). A linguagem fotográfica na formação do designer em um ambiente de convergência tecnológica. Rio de Janeiro, 2011. 145p. Tese de Doutorado - Departamento de Artes \& Design, Pontifícia Universidade Católica do Rio de Janeiro.

VELA, João Carlos. Design de produto: as concepções de formação pela perspectiva de seus docentes. São Paulo: Ed. Blucher, 2010. 